\title{
Fraseotermos de língua espanhola na denominação da avifauna do Pantanal Sul-mato-grossense: um estudo com base em materiais ornitológicos
}

DOI: http://dx.doi.org/10.21165/el.v50i3.2967

\section{Thierry Delmond ${ }^{1}$ \\ Elizabete Aparecida Marques ${ }^{2}$}

\section{Resumo}

Este artigo pretende apresentar os resultados preliminares de um estudo sobre fraseotermos da língua espanhola usados para denominar a avifauna do Pantanal Sul-mato-grossense, a partir de dados extraídos de materiais digitais ornitológicos. 0 trabalho apoia-se nos pressupostos teóricos e metodológicos da Teoria da Denominação (PETIT, 2009), da Terminologia (CABRÉ, 1998), da Socioterminologia (GAUDIN, 1993) e da Fraseologia (GONZÁLEZ-REY, 2015). Cada denominação é considerada, no domínio da Terminologia, como termo. No caso de uma análise de fraseologismos, o termo adequado para nomear as colocações terminológicas é fraseotermo. Os primeiros resultados mostram que os fraseotermos que nomeiam as aves do Pantanal sofrem uma forte influência sociocultural, o que corrobora a necessidade de um trabalho fraseoterminológico com base em critérios científicos.

Palavras-chave: Fraseoterminologia; fraseotermo; Ornitologia; Pantanal.

1 Universidade Federal de Mato Grosso do Sul (UFMS), Campo Grande, Mato Grosso do Sul, Brasil; thierry.delmond@hotmail.fr; https://orcid.org/0000-0003-2650-4779

2 Universidade Federal de Mato Grosso do Sul (UFMS), Campo Grande, Mato Grosso do Sul, Brasil; eamarques@hotmail.com; https://orcid.org/0000-0002-6308-9597 


\title{
Spanish phraseoterms in the denomination of the avifauna of the Pantanal Sul-mato-grossense: a study based on ornithological materials
}

\begin{abstract}
This article intends to present the preliminary results of a study on phraseoterms of the Spanish language used to name the Pantanal avifauna Sul-mato-grossense, from data extracted from ornithological digital materials. The work is based on the theoreticalmethodological assumptions of the theory of Denomination (PETIT, 2009), of Terminology (CABRÉ, 1998), of Socioterminology (GAUDIN, 1993), and of Phraseology (GONZÁLEZREY, 2015). Each denomination is considered, in the field of Terminology, as a term. In the case of an analysis of phraseologisms, the appropriate term for naming terminological placements is phraseoterm. The first results show that the phraseoterms that name birds in the Pantanal suffer a strong sociocultural influence, which corroborates the need for phraseoterminological work based on scientific criteria.
\end{abstract}

Keywords: Phraseoterminology; Phraseoterm; Ornithology; Pantanal.

\section{Introdução}

O Pantanal é uma ecorregião terrestre da América do Sul composta de prados e savanas inundadas durante parte do ano. Em razão de sua geografia de terras baixas, é a maior área úmida do planeta, atravessada por cursos de água que fluem durante a estação chuvosa. Mais de $80 \%$ do território pantaneiro se encontra submergido durante seis meses por ano, devido às chuvas torrenciais trazidas pelo "rio voador", proveniente da floresta amazônica (UNESCO, 2000).

A região é conhecida como um santuário ecológico onde vivem, segundo a última lista de aves de toda a planície pantaneira, 463 espécies, ou mais precisamente 500, considerando-se as residentes, migrantes e vagantes, algumas delas em grandes populações (FERNANDES; SIGNOR; PENHA, 2010), dentre as mais de 1919 espécies catalogadas em todo o Brasil, incluindo o Jabiru mycteria ou Tuiuiú ${ }^{3}$, a ave símbolo do Pantanal (PIACENTINI et al., 2015).

Mais informações sobre esse bioma podem ser adquiridas por meio de publicações científicas veiculadas por artigos, livros, páginas na internet acerca do tema, bem como o ecoturismo, os quais permitem popularizar o conhecimento, sobretudo, para um público de observadores de aves (SALVATI, 2002), brasileiros ou estrangeiros, em especial os

3 Nome grafado com a primeira letra maiúscula conforme as regras arbitrárias de nomenclatura das taxonomias, propostas por Linné em 1736. 
falantes de língua espanhola, dada a proximidade da região com países hispânicos, como a Bolívia e o Paraguai.

Com base no pensamento de Sapir (1969, p. 45), segundo o qual "o léxico da língua é que mais nitidamente reflete o ambiente físico e social dos falantes", a relação entre léxico, meio ambiente e cultura desperta alguns questionamentos que parecem ser relevantes quando se consideram as denominações das aves observadas no Pantanal em outras línguas, como o espanhol: levando em conta que o espanhol é a língua oficial de 21 países, existem diferenças (ou não) entre as denominações nesse idioma? Existe alguma relação entre a denominação da ave e o referente denominado? Que aspectos semânticos se destacam no processo de composição dos nomes das aves em língua espanhola?

Diante desses questionamentos, este trabalho pretende apresentar os resultados preliminares de um estudo sobre os fraseotermos da língua espanhola usados para denominar a avifauna do Pantanal Sul-mato-grossense, a partir de dados extraídos de materiais digitais ornitológicos. O trabalho está ancorado nos seguintes pressupostos teóricos: o conceito de denominação (MORTUREUX, 1984; THOIRON, 1994; PETIT, 2009), os postulados da Terminologia (CABRÉ, 1998; L'HOMME, 2004), da Socioterminologia (GAUDIN, 2003) e, para o conceito de fraseotermo, os trabalhos de González-Rey (2015) e Pamies Bertrán (2018).

Em primeiro lugar, o trabalho apresenta uma breve revisão teórica, seguida da descrição metodológica da pesquisa e, na sequência, expõe a análise dos dados e a discussão dos resultados.

\section{A palavra e a necessidade de nomear a realidade: da denominação à Terminologia}

As coisas, para terem existência no mundo humano, precisam ser nomeadas pelo homem. Como salienta Biderman (2001, p. 88), "é a partir da palavra que as entidades da realidade podem ser nomeadas e identificadas. A denominação dessas realidades cria um universo significativo revelado pela linguagem". Para serem entendidas e usadas pelo ser humano, as palavras precisam ser organizadas e definidas, um dos objetivos da Terminologia.

O termo terminologia só apareceu no século XVIII na escrita de um professor alemão, Christian Gottfried Schütz, seguido de uma definição em 1837 de William Whewell, epistemólogo, indicando que a terminologia é "um sistema dos termos usados na descrição dos objetos da história natural" (REY, 1979, p.7, tradução nossa).

4 No original: "Système des termes employés dans la description des objets de l'histoire naturelle". 
No século XX, o precursor moderno da Terminologia como ciência, Eugen Wüster, visando normalizar todos os termos científicos encontrados, propõe que as denominações devem refletir, o mais fielmente possível, o sistema conceitual e que, se houver uma intervenção na língua, é precisamente para reunir os dois (denominação e sistema conceitual), a fim de alcançar a biunivocidade (WÜSTER, 1998). Isso implica que uma denominação designa um conceito e que esse conceito é nomeado por um único termo. Historicamente, o aparecimento da Teoria clássica ou Geral da Terminologia (TGT) nasce, em 1930, com Eugen Wüster, que fornece as bases teóricas para a normalização dos termos relativos à industrialização.

Avançando no tempo, Cabré (1998), em sua Teoria Comunicativa da Terminologia (TCT), destaca a dimensão comunicativa da Terminologia, mas também seus aspectos cognitivos e linguísticos. Para uma abordagem diferente, mas não menos interessante, Faultstich (1998) e Gaudin (2003) consideram a Terminologia pelo viés de sua dimensão sociocultural, bem como seu aspecto político linguístico.

Os últimos anos viram novas propostas de abordagens terminológicas, como Terminologia Textual, que tem o texto como ponto de partida para a descrição do termo (BOURIGAULT; SLODZIAN, 1999).

\section{0 conceito de termo: diferentes perspectivas}

O conceito de termo pode ser discutido a partir de várias perspectivas. Para Wüster (1998, p. 30), o termo é uma denominação linguística materializando o conceito. Na visão de Cabré (1998, p. 149), os termos são as unidades básicas da Terminologia e denominam os conceitos próprios de cada disciplina especializada, favorecendo a comunicação entre especialistas. Na perspectiva de L'Homme (2005, p. 1113, tradução nossa), é "o resultado de uma associação entre um sentido e uma forma"5.

Essas propostas revelam a dificuldade de definir o termo, pois se trata de um poliedro com muitas facetas e cada uma das quais seria "uma porta de entrada para esse objeto complexo que é o termo" (L'HOMME, 2004, p. 54) ${ }^{6}$. Nesse sentido, o contexto de uso e o usuário em si afetam "a noção de termo que é sempre colorida pela perspectiva do especialista que a aborda"7 (L'HOMME, 2005, p. 1113, tradução nossa).

5 No original: "le résultat d'une association entre un sens et une forme.".

6 No original: "le terme est un polyèdre ayant de multiples facettes. Chacune de ces facettes constitue une porte d'entrée à cet objet complexe qu'est le terme".

7 No original: "la notion de 'terme' est toujours colorée par la perspective du spécialiste qui l'aborde.". 
Com relação à natureza da unidade terminológica que se propõe a investigar neste trabalho, ela é caracterizada como uma unidade polilexical e fixa, propriedades que podem ser observadas, inclusive, na própria taxonomia científica. Conforme Carl von Linné (1707-1778), o "pai da taxonomia moderna", o domínio da zoologia, no caso específico deste estudo o da Ornitologia, possui nomenclaturas binominais. Nessas denominações, o primeiro nome inicia-se por letra maiúscula e os formantes organizam-se de modo sistemático devendo ser classificados na sequência: classe, ordem, família, gênero, espécie, subespécie ou variedade (BARROS, 2007). Em um corpus de 278 aves das ordens dos não-passeriformes que embasa esta pesquisa, um total de aproximadamente $78 \%$ são nomes formados por dois ou mais itens lexicais.

No domínio da Fraseologia, um termo complexo, compreendido aqui como aquele formado por, no mínimo, duas unidades léxicas, vem sendo denominado como fraseotermo (GONZALEZ REY, 2015). Para Pamies Bertrán (2018), o fraseotermo está incluído dentro de uma categoria chamada Sintema, termo cunhado por Martinet (1999) para designar uma unidade linguística composta por, no mínimo, dois lexemas (fonte de cristalização e de idiomaticidade). É a menor unidade fraseológica. Nesse particular, é pertinente, em consonância com Lerat (1995, p. 20, tradução nossa ${ }^{8}$ ), examinar se os fraseotermos de uma área especializada podem se definir como um "conjunto de expressão denominando em uma língua natural as noções pertencentes a um domínio de conhecimento fortemente tematizado".

\section{A denominação no universo sociocultural}

A Socioterminologia, termo citado pela primeira vez por Boulanger em 1981, foi definida em seu artigo intitulado "Une lecture socioculturelle de la terminologie", em 1991. Nesse trabalho, o autor especifica que a perspectiva socioterminológica permite "atenuar os efeitos prescritivos exagerados de algumas proposições normativas. Toda terminologia é desenvolvida para fundamentar uma ciência, uma técnica e garantir-lhe um futuro, para trazê-la à vida, propagando-a por meio da comunicação a outras pessoas." (BOULANGER, 1991, p. 25, tradução nossa9).

Gaudin (2005, p. 82) concebe também a Terminologia pelo viés de sua dimensão sociocultural, bem como pelo seu viés político-linguístico. Surgida, para este autor, sob "a dupla influência da Sociolinguística teórica e da Sociolinguística de campo, a Socioterminologia tem como objeto o estudo da circulação dos termos em sincronia e

8 No original: "Un ensemble d'expressions dénommant dans une langue naturelle des notions relevant d'un domaine de connaissances fortement thématisé.".

9 No original: "Atténuer les effets prescriptifs exagérés de certaines propositions normatives. Toute terminologie est élaborée pour donner une assise à une science, à une technique et pour lui assurer un avenir, pour la faire vivre en la propageant par la communication à autrui.". 
diacronia, o que inclui a análise e a modelização de significados e conceituações ${ }^{10 "}$. Os conceitos terminológicos são vistos como construções de conhecimentos sujeitas a variações, sincrônicas e diacrônicas. Como explica Faultstich (2006, p. 28),

[...] a construção dos postulados teóricos que sustentam a teoria da variação em terminologia, propõe-se uma releitura da definição de termo, a fim de que se compreenda melhor por que um termo varia. Assim uma unidade terminológica pode ter ou assumir diferentes valores, de acordo com a função que uma dada variável desempenha nos contextos de ocorrência. E vale lembrar que termos são:

(i) signos que encontram sua funcionalidade nas linguagens de especialidade, de acordo com a dinâmica das línguas;

(ii) entidades variantes, porque fazem parte de situações comunicativas distintas;

(iii) itens do léxico especializado que passam por evoluções, por isso devem ser analisados no plano sincrônico e no plano diacrônico das línguas.

O estudo social de termos especializados questiona a maneira como eles aparecem, confrontando-os com sua própria produção de sentido. A observação da circulação das unidades terminológicas nas sociedades científıcas, mas também da sua apropriação pela população em geral, permite defınir as suas condições de emergência e transformações ao considerá-los como signos linguísticos e não como simples etiquetas de conceitos (GAUDIN, 2005).

No Brasil, Enilde Faultstich (1998 apud GAUDIN, 2005, p. 82) especifica que a Socioterminologia é "uma disciplina que se interessa pelo movimento do termo nas linguagens de especialidades". Sendo a Sociolinguística a abordagem mais social da linguística, no que diz respeito à Socioterminologia, as unidades terminológicas que constituem o discurso têm uma história. Desde a sua criação e evolução ao longo do tempo e das culturas, os termos em perpétuo movimento podem ser considerados como unidades histórico-socioculturais da língua. Eles refletem, por meio de sua constituição semântica e morfológica, a história, a cultura e os valores sociais dos povos que os usam ou os usaram.

Nessa perspectiva, formular um conceito, do ponto de vista da Socioterminologia, é nomear a realidade do mundo dos falantes de um domínio especializado. Na abordagem sociolinguística da Terminologia, a questão recai sobre a categorização dos elementos e, em particular, sobre a diferenciação entre designação e denominação na criação de

10 No original: "La double influence de la sociolinguistique théorique et de la socio linguistique de terrain, la socioterminologie se fixe comme objet l'étude de la circulation des termes en synchronie et en diachronie, ce qui inclut l'analyse et la modélisation des significations et des conceptualisations". 
termos, como na abordagem lexicológica da denominação. De acordo com Gaudin (2003), o objeto possui várias designações, entre as quais, em uma decisão última, uma delas será promovida à categoria de denominação. Nessa perspectiva, a designação é composta por elementos não lexicalizados ou, nesse caso, não terminologizados, pendentes de estabilização pelo uso em uma comunidade de especialistas. Esse princípio expõe o limite da terminologia normativa de Wüster, a qual não leva em consideração os usos e as necessidades de nomes das várias comunidades de falantes envolvidos (PETIT, 2009).

A dimensão sociolinguística do ato de denominar no contexto da superposição de denominação de direito e de fato é óbvia. Não é só o falante que influencia o ato denominativo, mas também o interlocutor, seu ambiente sociocultural e sua visão da realidade e do mundo circundante que inspiram a denominação e até a impõem. Nessa perspectiva, a neologia popularizante, portanto, a conceptualização, resulta de uma análise da realidade, análise esta que é diferente daquela realizada pelos produtores do termo científico original (MORTUREUX, 1984). Segundo esse mesmo autor, o domínio científico tem toda a sua importância para ilustrar o complexo funcionamento da denominação como um ato de linguagem, envolvendo a iniciativa de falantes, o públicoalvo, o jogo social da comunicação, a visão da realidade e as estruturas morfossintáticas e semânticas. O problema que pode ocorrer é o constante movimento da língua que muda com o passar do tempo porque, como bem indica Biderman (2001, p. 138), "a língua está em perpétuo movimento, seu caráter de inacabado e de devir está sempre presente". 0 ato de denominação encontra-se em uma perspectiva dinâmica de evolução, de movimento em que a observação da motivação dos termos "oferece um lugar de articulação entre as determinações socioculturais e as restrições linguísticas na atribuição de nomes [...] demonstrando a relação entre a estrutura formal do termo e seu sentido" (MORTUREUX, 1984, p. 110, tradução nossa ${ }^{11}$ ).

\section{Metodologia da pesquisa}

A metodologia desta pesquisa consistiu em utilizar a Web como recurso, mais precisamente o site Avibase, referência mundial em Ornitologia, para a construção de um corpus de estudo. Esse site, atualizado regularmente, é composto por um banco de dados da avifauna mundial. Resulta de um projeto de cooperação internacional para construir um conjunto de dados global da Ornitologia, baseado nas taxonomias mais relevantes, desde a década de 1990. Os dados que compõem o Avibase são provenientes das onze principais taxonomias científicas da avifauna do mundo, oferecendo seus nomes científicos latinos e, também, em mais de trinta línguas diferentes. Uma descrição de cada ave, sua classificação sistêmica, várias fotos certificadas pela comunidade científica e, também, uma biblioteca de sons para cada uma completam as denominações.

11 No original: "offre un lieu d'articulation entre les déterminations socio-culturelles et les contraintes linguistiques dans l'attribution des noms [...] en manifestant la relation entre la structure formelle du terme et son sens". 
O processo de extração de dados consistiu, inicialmente, em localizar no site Avibase as informações acerca de cada ave, utilizando a fonte HTML das páginas. Para isso, o uso da linguagem "Xquery" e "Python" possibilitou a realização de script de solicitação nas páginas, a fim de extrair as denominações, conforme duas etapas.

A primeira consistiu em recuperar os nomes das aves e as URLs correspondentes. $\mathrm{Na}$ URL do Avibase: https://avibase.bsc-eoc.org/checklist.jsp?region=BRms

Obteve-se uma lista das denominações das aves, o identificador de cada uma e as URLs relacionadas. As URLs obtidas têm o seguinte formato:

"species.jsp? avibaseid = <identifier $>$ "

A segunda etapa permitiu recuperar as informações acerca da ave escolhida. Com um script elaborado na linguagem Xquery e dentro do qual foram inseridos os identificadores Avibase de cada ave, foi possível recuperar todo o conteúdo da página de uma determinada ave. Há uma certa quantidade de informações nessa página, incluindo denominações em diferentes idiomas.

A extração planejada considerou as aves das ordens dos não-passeriformes, segundo a taxonomia de Clements (2019), presentes no território do Pantanal de Mato Grosso do Sul. Constituiu-se uma base de denominações referente a 278 aves, com correspondentes em 40 idiomas diferentes, dentre os quais o espanhol.

O resultado do processo é a geração de uma tabela no formato $X M L$, transformada em formato CSV, que permite navegar rapidamente, pois cada linha corresponde a uma ave e cada coluna, exceto a primeira que é o identificador do Avibase, corresponde a uma denominação em uma determinada língua. Uma vez extraídos os dados, foi realizada a seleção e organização das denominações das aves de todos os países de língua espanhola, indicados na base de dados inicial, ou seja, os nomes espanhóis correspondentes às 278 aves de 18 países hispanófonos, a maioria da América do Sul e Central, incluindo também a Espanha e Cuba.

Para este trabalho, foram selecionadas três aves, levando em conta seu pertencimento a diferentes ordens e famílias no nível taxonômico. Posteriormente, as denominações para as três aves (Maçarico-de-perna-amarela, Coruja-buraqueira e Mergulhão-caçador) foram submetidas a uma análise léxico-semântica dos diferentes elementos de nomeação para identificar os semas, com base nos pressupostos teóricos da Terminologia Multilíngue de Thoiron (1994), da Escola de Lyon. Segundo essa teoria, um conceito é divisível em traços conceituais e um termo/fraseotermo é divisível em elementos de nomeação, sendo eles mesmos divisíveis em um ou mais morfemas. A cada nível, há possibilidade de produção 
de sentido. O auxílio de referências dicionarísticas e científicas, como o Diccionario de la lengua española de la Real Academia Española (DRAE), Dicionário online Linguee, Dicionário de Tupi Moderno (BOUDIN, 2005) e a obra de Ornitologia de Frisch, J. e Frisch, C. (2005), durante as análises, possibilitou desvelar os semas nas unidades de nomeação.

\section{Análise dos dados e discussão dos resultados}

No recorte investigado neste trabalho, os dados evidenciaram que, das três aves estudadas, a que tem maior número de denominações de caráter fraseológico, ou fraseotermos, em língua espanhola é o Maçarico-de-perna-amarela, com 15 formas diferentes, considerando todas as variações de forma da palavra. Em segundo lugar, com 14 formas diferentes, aparecem os fraseotermos usados para denominar a Corujaburaqueira e, em terceiro, com nove formas, os fraseotermos que nomeiam o Mergulhãocaçador. Reitera-se que, dadas as delimitações do gênero artigo científıco, apresenta-se uma amostragem da análise léxico-semântica de três aves escolhidas aleatoriamente, considerando-se, entretanto, que elas pertencem a diferentes ordens e famílias no nível taxonômico. Ressalta-se, ainda, que o fato de nem todos os países de língua espanhola estarem representados, não significa que eles não tenham denominações para as aves em questão. Neste caso, algum tipo de restrição imposta pelo corpus pode justificar, por exemplo, a fato de a Bolívia, que possui uma vasta área fronteiriça com o Pantanal Sulmato-grossense, não registrar denominações para duas das três aves analisadas. Outra justificativa pode ser a restrição imposta pelo tipo de unidade lexical investigada que se limita às lexias complexas.

\section{Denominações em língua espanhola para Maçarico-de-perna- amarela}

O quadro, a seguir, mostra a distribuição dos fraseotermos em língua espanhola para denominar o Maçarico-de-perna-amarela (Tringa flavipes) por países, conforme os dados fornecidos pelo corpus da pesquisa.

Quadro 1. Fraseotermos em língua espanhola para Maçarico-de-perna-amarela

\begin{tabular}{|l|l|c|}
\hline \multicolumn{2}{|c|}{ Fraseotermos } & Países \\
\hline 1 & Andarríos patiamarillo & Colômbia \\
\hline 2 & Andarríos patigualdo chico & Nicarágua \\
\hline 3 & Archibebe patigualdo chico & Espanha \\
\hline 4 & Chorlito patas amarillas & Uruguai \\
\hline 5 & Patamarilla menor & México \\
\hline 6 & Patiamarillo chico & Colômbia \\
\hline
\end{tabular}




\begin{tabular}{|l|l|c|}
\hline 7 & Patiamarillo menor & Costa Rica; Equador; Panamá \\
\hline 8 & Playero menor de patas amarillas & Honduras \\
\hline 9 & Playero menor patas amarillas & Uruguai \\
\hline 10 & Playera pata amarilla menor & Uruguai \\
\hline 11 & Playero patas amarillas chico & Paraguai \\
\hline 12 & Pitotoi chico & Argentina; Chile \\
\hline 13 & Pitotoy chico & Venezuela \\
\hline 14 & Tigüi-Tigüe Chico & Cuba \\
\hline 15 & Zarapico patiamarillo chico & \\
\hline
\end{tabular}

Fonte: Elaboração própria

Como se pode observar na tabela, as formas andarríos patiamarillo e andarríos patigualdo chico são observadas na Colômbia e Nicarágua, respectivamente, enquanto a Espanha registra archibebe patigualdo chico para denominar o maçarico-de-perna-amarela. A forma patiamarillo menor aparece registrada na Costa Rica, Equador e Panamá enquanto pitotoy chico e sua variante pitotoi chico tiveram registro na Argentina, Chile e Paraguai. Por sua vez, Honduras, Uruguai e Peru registram a forma playero menore suas variantes enquanto Venezuela e Cuba apresentam denominações como tigüi-tigüe chico e zarapico patiamarillo chico. O Uruguai registra várias denominações. Além das já mencionadas, apresenta, ainda, chorlito patas amarilla.

Do ponto de vista semântico, os fraseotermos pitotoy chico/pitotoi chico podem ser explicados pela onomatopeia pitotoy, grito que emite a ave no início do voo somado ao sema do tamanho, pois o referente é menor em relação a outros de sua espécie. Note-se que o tamanho do referente também está presente em quase todas as denominações, combinando-se com outras informações semânticas relativas ao referente.

Nesse sentido, as formas patamarilla menor, patamarillo chico, patamarillo menor aludem à cor amarelada das patas da ave, traço que se encontra nas formas sustentadas pelo pivô terminológico (GOUADEC, 1983) playero, como playero menor de patas amarillas, playero menor patas amarillas, playero patas amarillas chico e playera pata amarilla. O pivô playero e sua variante de gênero playera comportam um sema que diz respeito ao habitat natural da ave, margem de rios, lagos, lagoas, etc. De igual modo, as formas andarríos patiamarillo e andarríos patigualdo chico possuem traços semânticos que indicam o habitat por onde as aves têm o hábito de caminhar. É interessante observar que a alusão à cor aparece de forma metafórica em patigualdo, ou seja, patas amarelas como a flor da gualda, como ocorre em andarríos patigualdo chico e archibebe patigualdo chico. Outras denominações aportam outros traços relativos à forma do referente, como o bico em zarapico patiamarillo chico. Nesse caso, o morfema zara remete a comprido como uma espiga de painço. 0 quadro abaixo resume a análise léxico semântica realizada. 
Quadro 2. Análise léxico-semântica das denominações do Maçarico-de-perna-amarela

\begin{tabular}{|c|c|c|c|c|}
\hline Língua & Denominação & $\begin{array}{c}\text { Elementos de } \\
\text { nomeação }\end{array}$ & Semas & Referências \\
\hline Latim & $\begin{array}{l}\text { Tringa } \\
\text { flavipes }\end{array}$ & 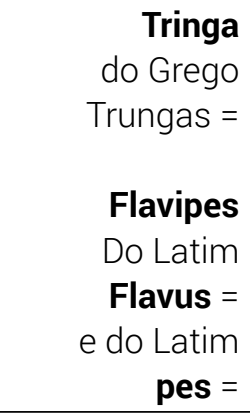 & $\begin{array}{l}\text { Ave ribeirinha, do tamanho de } \\
\text { um Sabiá (mencionada por } \\
\text { Aristóteles) } \\
\text { Amarelo } \\
\text { Pé }\end{array}$ & Fritsch (2005) \\
\hline $\begin{array}{c}\text { Português } \\
\text { do Brasil }\end{array}$ & $\begin{array}{l}\text { Maçarico- } \\
\text { de-perna- } \\
\text { amarela }\end{array}$ & $\begin{array}{r}\text { Maçarico }= \\
\text { perna }= \\
\text { amarela }=\end{array}$ & $\begin{array}{l}\text { Relação às cores pardas do fogo } \\
\text { do maçarico } \\
\text { Perna } \\
\text { Cor amarela } \\
\end{array}$ & Aulete Digital \\
\hline Argentina & Pitotoy chico & $\begin{array}{l}\text { Pitotoy }= \\
\text { chico }=\end{array}$ & $\begin{array}{l}\text { Vem da onomatopeia "Pitotoy", } \\
\text { grito que ele emite no início do } \\
\text { voo; } \\
\text { Pequeno ou menor em tamanho } \\
\text { do que outros de sua espécie } \\
\end{array}$ & DRAE \\
\hline Chile & Pitotoy chico & $\begin{array}{l}\text { Pitotoy }= \\
\text { chico }=\end{array}$ & $\begin{array}{l}\text { Vem da onomatopeia "Pitotoy", } \\
\text { grito que ele emite no início do } \\
\text { voo; } \\
\text { Pequeno ou menor em tamanho } \\
\text { do que outros de sua espécie } \\
\end{array}$ & DRAE \\
\hline Colômbia & $\begin{array}{l}\text { Andarríos } \\
\text { patiamarillo } \\
\text { Patiamarillo } \\
\text { chico }\end{array}$ & $\begin{array}{r}\text { Andar }= \\
\text { ríos }= \\
\text { pati }=\text { pata }= \\
\text { amarillo }= \\
\text { chico }=\end{array}$ & $\begin{array}{l}\text { Andar } \\
\text { Rios } \\
\text { Pata, pé } \\
\text { Amarelo } \\
\text { Pequeno ou menor em tamanho } \\
\text { do que outros de sua espécie }\end{array}$ & DRAE \\
\hline $\begin{array}{l}\text { Costa } \\
\text { Rica }\end{array}$ & $\begin{array}{l}\text { Patiamarillo } \\
\text { menor }\end{array}$ & $\begin{array}{r}\text { pati }=\text { pata }= \\
\text { amarillo }= \\
\text { menor }=\end{array}$ & \begin{tabular}{|l} 
Pata, pé \\
Amarelo \\
Menor em tamanho \\
\end{tabular} & DRAE \\
\hline Cuba & $\begin{array}{l}\text { Zarapico } \\
\text { patiamarillo } \\
\text { chico }\end{array}$ & $\begin{aligned} \text { Zara } & = \\
\text { Pico } & = \\
\text { pati }=\text { pata } & = \\
\text { amarillo } & = \\
\text { chico } & =\end{aligned}$ & $\begin{array}{l}\text { Comprido como a espiga de } \\
\text { painço, de trigo } \\
\text { Bico } \\
\text { Pata, pé } \\
\text { Amarelo } \\
\text { Pequeno ou menor em tamanho } \\
\text { do que outros de sua espécie }\end{array}$ & DRAE \\
\hline
\end{tabular}




\begin{tabular}{|c|c|c|c|c|}
\hline Espanha & $\begin{array}{l}\text { Archibebe } \\
\text { patigualdo } \\
\text { chico }\end{array}$ & $\begin{array}{r}\text { Archibebe }= \\
\text { pati }=\text { pata }= \\
\text { gualdo }= \\
\text { chico }=\end{array}$ & $\begin{array}{l}\text { Ave muito turbulenta, aterroriza } \\
\text { outras aves para defender o seu } \\
\text { território, mesmo as maiores, } \\
\text { não é nada amigável. } \\
\text { Pata, pé } \\
\text { Amarela como a flor da gualda } \\
\text { Pequeno ou menor em tamanho } \\
\text { do que outros de sua espécie }\end{array}$ & DRAE \\
\hline Equador & $\begin{array}{l}\text { Patiamarillo } \\
\text { menor }\end{array}$ & $\begin{array}{r}\text { pati }=\text { pata }= \\
\text { amarillo }= \\
\text { menor }=\end{array}$ & $\begin{array}{l}\text { Pata, pé } \\
\text { Amarelo } \\
\text { Menor em tamanho }\end{array}$ & Linguee \\
\hline Honduras & $\begin{array}{l}\text { Playero } \\
\text { menor } \\
\text { de patas } \\
\text { amarillas }\end{array}$ & $\begin{array}{r}\text { Playero }= \\
\text { menor }= \\
\text { patas }= \\
\text { amarillas }=\end{array}$ & $\begin{array}{l}\text { Que apanha os peixes na beira } \\
\text { da água para comê-los } \\
\text { Menor em tamanho } \\
\text { Patas, pés } \\
\text { Amarelas }\end{array}$ & $\begin{array}{l}\text { DRAE } \\
\text { Linguee }\end{array}$ \\
\hline México & $\begin{array}{c}\text { Patamarilla } \\
\text { menor }\end{array}$ & $\begin{array}{r}\text { pata }= \\
\text { amarillo }= \\
\text { menor }=\end{array}$ & $\begin{array}{l}\text { Pata, pé } \\
\text { Amarelo } \\
\text { Menor em tamanho }\end{array}$ & Linguee \\
\hline Nicarágua & $\begin{array}{l}\text { Andarríos } \\
\text { patigualdo } \\
\text { Chico }\end{array}$ & $\begin{array}{r}\text { Andar }= \\
\text { ríos }= \\
\text { pati }=\text { pata }= \\
\text { gualdo }= \\
\text { chico }=\end{array}$ & $\begin{array}{l}\text { Andar } \\
\text { Rios } \\
\text { Pata, pé } \\
\text { Amarela como a flor da gualda } \\
\text { Pequeno ou menor em tamanho } \\
\text { do que outros de sua espécie } \\
\end{array}$ & $\begin{array}{l}\text { DRAE } \\
\text { Linguee }\end{array}$ \\
\hline Panamá & $\begin{array}{c}\text { Patiamarillo } \\
\text { menor }\end{array}$ & $\begin{array}{r}\text { Patia }=\text { pata }= \\
\text { amarillo }= \\
\text { menor }=\end{array}$ & $\begin{array}{l}\text { Pata, pé } \\
\text { Amarelo } \\
\text { Menor em tamanho }\end{array}$ & Linguee \\
\hline Paraguai & Pitotoi chico & $\begin{array}{l}\text { Pitotoi }= \\
\text { chico }=\end{array}$ & $\begin{array}{l}\text { Vem da onomatopeia "Pitotoi", } \\
\text { grito que ele emite no início do } \\
\text { voo } \\
\text { Pequeno ou menor em tamanho } \\
\text { do que outros de sua espécie }\end{array}$ & $\begin{array}{l}\text { DRAE } \\
\text { Linguee }\end{array}$ \\
\hline Peru & $\begin{array}{l}\text { Playera pata } \\
\text { amarilla } \\
\text { menor }\end{array}$ & $\begin{array}{r}\text { Playero }= \\
\text { pata }= \\
\text { amarilla }= \\
\text { menor }=\end{array}$ & $\begin{array}{l}\text { Que apanha os peixes na beira } \\
\text { da água para comê-los } \\
\text { Pata, pé } \\
\text { Amarela } \\
\text { Menor em tamanho }\end{array}$ & $\begin{array}{l}\text { DRAE } \\
\text { Linguee }\end{array}$ \\
\hline
\end{tabular}




\begin{tabular}{|c|c|c|c|c|}
\hline Uruguai & $\begin{array}{l}\text { Chorlito patas } \\
\text { amarillas } \\
\text { Playero } \\
\text { menor patas } \\
\text { amarillas } \\
\text { Playero patas } \\
\text { amarillas } \\
\text { Chico }\end{array}$ & $\begin{array}{r}\text { Chorlito } \\
\text { de chorla }+ \\
\text { diminutivo }= \\
\text { patas = } \\
\text { amarillas = } \\
\text { Playero = } \\
\text { menor = } \\
\text { chico = }\end{array}$ & $\begin{array}{l}\text { Vem da onomatopeia "chorlito", } \\
\text { grito da ave } \\
\text { Patas, pés } \\
\text { Amarelas } \\
\text { Que apanha os peixes na beira } \\
\text { da água para comê-los } \\
\text { Menor em tamanho } \\
\text { Pequeno ou menor em tamanho } \\
\text { do que outros de sua espécie }\end{array}$ & $\begin{array}{l}\text { DRAE } \\
\text { Linguee }\end{array}$ \\
\hline Venezuela & $\begin{array}{l}\text { Tigüi-Tigüe } \\
\text { Chico }\end{array}$ & $\begin{array}{r}\text { Ti (guaraní) } \\
\text { pico = } \\
\text { güi (guaraní) }= \\
\text { Tigüe }= \\
\text { chico }=\end{array}$ & $\begin{array}{l}\text { Bico } \\
\text { Inquieto } \\
\text { Diz-se de um jovem de raça } \\
\text { negra } \\
\text { Pequeno ou menor em tamanho } \\
\text { do que outros de sua espécie }\end{array}$ & $\begin{array}{l}\text { DRAE } \\
\text { Linguee }\end{array}$ \\
\hline
\end{tabular}

Fonte: Elaboração própria

\section{Denominações em língua espanhola para Coruja-buraqueira}

No recorte dos dados levantados, a Coruja-buraqueira (Athene cunicularia) registrou 14 denominações fraseoterminológicas em língua espanhola, conforme observado no quadro subsequente.

Quadro 3. Fraseotermos em língua espanhola para Coruja-buraqueira

\begin{tabular}{|l|l|c|}
\hline \multicolumn{2}{|c|}{ Fraseotermos } & Países \\
\hline 1 & Búho llanero & Colômbia; México \\
\hline 2 & Búho terrestre & Panamá; Equador \\
\hline 3 & Lechucita de campo & Uruguai \\
\hline 4 & Lechucita de las viscacheras & Argentina; Bolívia \\
\hline 5 & Lechucita vizcachera & Paraguai \\
\hline 6 & Lechuza común & Uruguai \\
\hline 7 & Lechuza rojiza & Uruguai \\
\hline 8 & Lechuza terrestre & Peru; Costa Rica \\
\hline 9 & Mochuelo conejo & Colômbia \\
\hline 10 & Mochuelo de hoyo & Venezuela \\
\hline 11 & Mochuelo de madriguera & Espanha \\
\hline 12 & Mochuelo terrero & Colômbia \\
\hline
\end{tabular}




\begin{tabular}{|l|l|c|}
\hline 13 & Sijú de Sabana & Cuba \\
\hline 14 & Tecolote llanero & México \\
\hline
\end{tabular}

Fonte: Elaboração própria

A análise léxico-semântica mostra que, em todas as denominações, os pivôs fraseoterminológicos lechuza e sua variante lechucita, búho, mochuelo, sijú e tecolote correspondem ao português coruja que, por sua vez, define-se como "ave de rapina de cabeça arredondada e olhos enormes, captura ratos, morcegos, pequenos répteis e invertebrados" (AULETE DIGITAL). Alguns desses nomes são de origem indígena, como sijú e tecolote que, segundo o DRAE, são de Caribe e Náhuatl (língua Uto-asteca), respectivamente. Já mochuelo, conforme o mesmo dicionário, é de origem incerta. O que varia são os elementos especificativos que carregam traços semânticos relacionados com:

- Habitat da ave: lugar onde ela vive e se reproduz, que pode ser qualquer cavidade na terra, natural ou escavada, como a vizcachera (toca da vizcacha), a madriguera (caverna onde vivem certos animais) e o hoyo (concavidade formada na terra) ou, ainda, a planície o campo e a savana. Destacam-se as denominações lechucita vizcachera/de las vizcacheras, lechucita de campo, mochuelo de hoyo/de madriguera, sijú de sabana, além de búho/tecolote Ilanero, búho/lechuza terrestre e mochuelo terrero. A denominação mochuelo conejo pode aludir, por analogia, a uma característica compartilhada pela coruja em questão e o coelho, que costumam habitar em covas.

- Cor da ave: traço que pode ser observado em lechuza rojiza, em que rojiza tem como referência a cor que tem um tom de vermelho.

- Abundância da ave: traço que pode ser observado em lechuza común. 
Quadro 4. Análise léxico-semântica das denominações da Coruja-buraqueira

\begin{tabular}{|c|c|c|c|c|}
\hline Língua & Denominação & $\begin{array}{c}\text { Elementos de } \\
\text { nomeação }\end{array}$ & Semas & Referências \\
\hline Latim & $\begin{array}{l}\text { Athene } \\
\text { cunicularia }\end{array}$ & $\begin{array}{r}\text { Athene } \\
\text { do Grego Atena = } \\
\text { Cunicularia } \\
\text { Do Latim } \\
\text { cunicularius = }\end{array}$ & $\begin{array}{l}\text { Divindade grega } \\
\text { Mineiro, passagem ou } \\
\text { caminho no subsolo, numa } \\
\text { mina subterrânea }\end{array}$ & $\begin{array}{l}\text { Fritsch } \\
(2005)\end{array}$ \\
\hline $\begin{array}{l}\text { Português } \\
\text { do Brasil }\end{array}$ & $\begin{array}{l}\text { Coruja- } \\
\text { buraqueira }\end{array}$ & $\begin{array}{r}\text { Coruja }= \\
\text { Subst. buraco }= \\
+ \text { sufixo eira }=\end{array}$ & $\begin{array}{l}\text { Aves de rapina, de cabeça } \\
\text { arredondada e olhos } \\
\text { enormes, captura ratos, } \\
\text { morcegos, pequenos } \\
\text { répteis e invertebrados. } \\
\text { Qualquer concavidade na } \\
\text { terra, natural ou escavada } \\
\text { Indicando a ideia de } \\
\text { relação, local }\end{array}$ & $\begin{array}{l}\text { Aulete } \\
\text { Digital }\end{array}$ \\
\hline Argentina & $\begin{array}{l}\text { Lechucita de } \\
\text { las viscacheras } \\
\text { Lechucita } \\
\text { vizcachera }\end{array}$ & $\begin{array}{r}\text { Lechucita de } \\
\text { Lechuza = } \\
\text { Sufixo ita = } \\
\text { Vis(z)cachera(s) = } \\
\text { vizcacha (de } \\
\text { origem quechua) = }\end{array}$ & $\begin{array}{l}\text { Coruja } \\
\text { Diminutivo, pequena } \\
\text { Toca da vizcacha } \\
\text { Roedor noturno típico das } \\
\text { grandes planícies. Constrói } \\
\text { complexas colônias de } \\
\text { cavernas onde ele vive } \\
\text { no Peru, Bolívia, Chile e } \\
\text { Argentina } \\
\end{array}$ & $\begin{array}{l}\text { DRAE } \\
\text { Linguee }\end{array}$ \\
\hline Bolívia & $\begin{array}{l}\text { Lechucita de } \\
\text { las viscacheras }\end{array}$ & $\begin{array}{r}\text { Lechucita de } \\
\text { Lechuza }= \\
+ \text { sufixo ita }= \\
\text { Vis(z)cachera(s) }= \\
\text { vizcacha }(\text { de } \\
\text { origem quechua) }=\end{array}$ & $\begin{array}{l}\text { Coruja } \\
\text { Diminutivo, pequena } \\
\text { Toca da vizcacha } \\
\text { Roedor noturno típico das } \\
\text { grandes planícies. Constrói } \\
\text { complexas colônias de } \\
\text { cavernas onde ele vive } \\
\end{array}$ & $\begin{array}{l}\text { DRAE } \\
\text { Linguee }\end{array}$ \\
\hline Chile & Pequén & $\begin{array}{l}\text { Do Mapuche } \\
\text { pequeñ = }\end{array}$ & $\begin{array}{l}\text { Ave de rapina diurna, muito } \\
\text { semelhante à coruja, mas } \\
\text { menor }\end{array}$ & DRAE \\
\hline
\end{tabular}




\begin{tabular}{|c|c|c|c|c|}
\hline Colômbia & $\begin{array}{l}\text { Búho llanero } \\
\text { Mochuelo } \\
\text { conejo } \\
\text { Mochuelo } \\
\text { terrero }\end{array}$ & $\begin{array}{r}\text { Búho do Latim } \\
\text { bubo = } \\
\text { Ilanero = } \\
\text { Mochuelo = } \\
\text { Conejo do Latim } \\
\text { cunicŭlus = } \\
\text { terrero do Latim } \\
\text { terrarius = }\end{array}$ & $\begin{array}{l}\text { Coruja } \\
\text { Habitante das planícies } \\
\text { Ave de rapina, semelhante } \\
\text { à coruja, mas de menor } \\
\text { tamanho } \\
\text { Mamífero com cerca de } \\
40 \mathrm{~cm} \text { de comprimento, } \\
\text { vivendo em tocas } \\
\text { Pertencendo à terra }\end{array}$ & $\begin{array}{l}\text { DRAE } \\
\text { Linguee }\end{array}$ \\
\hline Costa Rica & $\begin{array}{l}\text { Lechuza } \\
\text { terrestre }\end{array}$ & $\begin{array}{r}\text { Lechuza = } \\
\text { terrestre do Latim } \\
\text { terrestris = }\end{array}$ & $\begin{array}{l}\text { Coruja } \\
\text { Pertencendo ou } \\
\text { relacionando-se com a } \\
\text { Terra }\end{array}$ & DRAE \\
\hline Cuba & Sijú de Sabana & $\begin{array}{r}\text { Sijú = } \\
\text { Sabana (de origem } \\
\text { Caribe) }=\end{array}$ & $\begin{array}{l}\text { Ave de rapina das Antilhas } \\
\text { Planície, muita extensa e } \\
\text { sem vegetação arbórea }\end{array}$ & DRAE \\
\hline Espanha & $\begin{array}{l}\text { Mochuelo de } \\
\text { madriguera }\end{array}$ & $\begin{array}{l}\text { Mochuelo = } \\
\text { madriguera = }\end{array}$ & $\begin{array}{l}\text { Ave de rapina, semelhante } \\
\text { à coruja, mas de menor } \\
\text { tamanho } \\
\text { Caverna onde vivem certos } \\
\text { animais }\end{array}$ & DRAE \\
\hline Equador & Búho terrestre & $\begin{array}{r}\text { Búho do Latim } \\
\text { bubo = } \\
\text { terrestre do Latim } \\
\text { terrestris = }\end{array}$ & $\begin{array}{l}\text { Coruja } \\
\text { Pertencendo ou } \\
\text { relacionando-se com a } \\
\text { Terra }\end{array}$ & DRAE \\
\hline México & $\begin{array}{l}\text { Búho llanero } \\
\text { Tecolote llanero }\end{array}$ & $\begin{array}{r}\text { Búho do Latim } \\
\text { bubo= } \\
\text { Ilanero = } \\
\text { Tecolote } \\
\text { do Náhuatl } \\
\text { (língua Uto- } \\
\text { asteca) tecolotl = }\end{array}$ & $\begin{array}{l}\text { Coruja } \\
\text { Habitante das planícies } \\
\text { Búho, ave de rapina }\end{array}$ & $\begin{array}{l}\text { DRAE } \\
\text { Linguee }\end{array}$ \\
\hline Panamá & Búho terrestre & $\begin{array}{r}\text { Búho = } \\
\text { terrestre do Latim } \\
\text { terrestris = }\end{array}$ & $\begin{array}{l}\text { Coruja } \\
\text { Pertencendo } \\
\text { relacionando-se com a } \\
\text { Terra }\end{array}$ & DRAE \\
\hline
\end{tabular}




\begin{tabular}{|c|c|c|c|c|}
\hline Paraguai & $\begin{array}{l}\text { Lechucita } \\
\text { vizcachera }\end{array}$ & $\begin{array}{r}\text { Lechucita de } \\
\text { Lechuza }= \\
+ \text { sufixo ita }= \\
\text { Vizcachera }= \\
\text { vizcacha }(\text { de } \\
\text { origem quechua) }=\end{array}$ & \begin{tabular}{|l|} 
Coruja \\
Diminutivo, pequena \\
Toca da vizcacha \\
Roedor noturno típico das \\
grandes planícies. Constrói \\
complexas colônias de \\
cavernas onde ele vive
\end{tabular} & DRAE \\
\hline Peru & $\begin{array}{l}\text { Lechuza } \\
\text { Terrestre }\end{array}$ & $\begin{array}{r}\text { Lechuza = } \\
\text { terrestre do Latim } \\
\text { terrestris = }\end{array}$ & 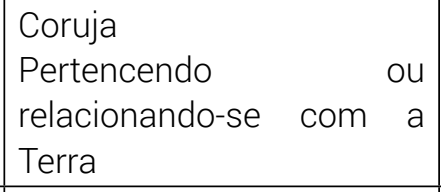 & DRAE \\
\hline Uruguai & $\begin{array}{l}\text { Lechucita de } \\
\text { campo } \\
\text { Lechuza } \\
\text { común } \\
\text { Lechuza rojiza }\end{array}$ & $\begin{array}{r}\text { Lechucita de } \\
\text { Lechuza }= \\
+ \text { sufixo ita }= \\
\text { campo }= \\
\text { Lechuza }= \\
\text { común }= \\
\text { rojiza }=\end{array}$ & $\begin{array}{l}\text { Coruja } \\
\text { Diminutivo, pequena } \\
\text { Campo } \\
\text { Coruja } \\
\text { Común } \\
\text { Disse de uma cor: isso } \\
\text { puxa o vermelho } \\
\end{array}$ & $\begin{array}{l}\text { DRAE } \\
\text { Linguee }\end{array}$ \\
\hline Venezuela & $\begin{array}{l}\text { Mochuelo de } \\
\text { hoyo }\end{array}$ & $\begin{array}{r}\text { Mochuelo }= \\
\text { hoyo }=\end{array}$ & $\begin{array}{l}\text { Ave de rapina, semelhante } \\
\text { à coruja, mas de menor } \\
\text { tamanho } \\
\text { Concavidader ou } \\
\text { profundidade formada na } \\
\text { terra }\end{array}$ & DRAE \\
\hline
\end{tabular}

Fonte: Elaboração própria

\section{Denominações em língua espanhola para Mergulhão-caçador}

O quadro, a seguir, reúne as denominações de caráter fraseoterminológico em língua espanhola para mergulhão-caçador, distribuídas por países de fala hispânica.

Quadro 5. Fraseotermos em língua espanhola para Mergulhão-caçador

\begin{tabular}{|l|l|c|}
\hline \multicolumn{2}{|c|}{ Fraseotermos } & Países \\
\hline 1 & Macá pico grueso & Argentina, Paraguai \\
\hline 2 & Zambullidor de pico grueso & Peru, Uruguai \\
\hline 3 & Zambullidor pico grueso & México \\
\hline 4 & Zambullidor picogrueso & México \\
\hline 5 & Zambullidor pico rayado & Honduras \\
\hline
\end{tabular}




\begin{tabular}{|l|l|c|}
\hline 6 & Zambullidor piquigrueso & Colômbia \\
\hline 7 & Zambullidor piquipinto & Colômbia, Costa Rica, Equador, México, Panamá \\
\hline 8 & Zampullín Piquipinto & Nicarágua \\
\hline 9 & Zaramagullón grande & Cuba, Espanha \\
\hline
\end{tabular}

Fonte: Elaboração própria

Como ocorre em português, a denominação desta ave em espanhol também se explica por uma das principais características do referente: o hábito de mergulhar em busca de alimento, acrescidas de outros traços relacionados com a forma, o tamanho e as cores da ave. Nesse sentido, o pivô zambullidor (mergulhador, em português) é modificado por informações semânticas sobre o bico da ave, como zambullidor de pico grueso e zambullidor pico grueso (sem a preposição), zambullidor picogrueso e zambullidor piquigrueso, que fazem alusão à espessura do bico da ave. Por sua vez, a forma zambullidor pico rayado aporta a informação de que o bico do referente é listrado enquanto a denominação zambullidor piquipinto alude às diversas cores do bico da ave. É interessante observar, ainda, que nem todas as denominações reportam à característica de ave mergulhadora. É o que se nota em zaumpullín piquipinto que contêm o sema de ave ribeirinha, acrescido de informações semânticas, como piqui (bico) + pinto (várias cores). Na denominação argentina e paraguaia macá pico grueso, a unidade lexical macá é de origem tupi-guarani e significa movimentação abaixo da água. Note-se que o traço abaixo da água se encontra, também, em zaramagullón (somormujo = abaixo da água + sufıxo -ón = grande).

Quadro 6. Análise léxico-semântica das denominações do Mergulhão-caçador

\begin{tabular}{|c|l|r|l|l|}
\hline Língua & Denominação & $\begin{array}{r}\text { Elementos de } \\
\text { nomeação }\end{array}$ & Semas & Referências \\
\hline Latim & $\begin{array}{l}\text { Podilymbus } \\
\text { podiceps }\end{array}$ & $\begin{array}{r}\text { Podiceps = do } \\
\text { Latim podex },\end{array}$ & $\begin{array}{l}\text { Pernas posicionadas na } \\
\text { parte traseira, na borda } \\
\text { externa do corpo } \\
\text { podicis }= \\
\text { Sinônimo de Podiceps } \\
\text { abertura e pes = } \\
\text { pês }=\end{array}$ & Fritsch (2005) \\
Podilymbus $=$ & $\begin{array}{r}\text { Mergulhão }= \\
\text { Caçador }=\end{array}$ & $\begin{array}{l}\text { Grande mergulho } \\
\text { Que costuma caçar para } \\
\text { alimentação por instinto }\end{array}$ & Aulete Digital \\
\hline $\begin{array}{l}\text { Português } \\
\text { do Brasil }\end{array}$ & $\begin{array}{l}\text { Mergulhão- } \\
\text { caçador }\end{array}$ & & \\
\hline
\end{tabular}




\begin{tabular}{|c|c|c|c|c|}
\hline Argentina & $\begin{array}{l}\text { Macá pico } \\
\text { grueso }\end{array}$ & $\begin{array}{r}\text { Macá = } \\
\text { do Tupi-Guarani } \\
\text { Macang ou } \\
\text { Muaka'í = } \\
\text { pico = } \\
\text { grueso = }\end{array}$ & $\begin{array}{l}\text { Palmípedes das áreas } \\
\text { lacustres, que se } \\
\text { caracterizam pela ausência } \\
\text { de penas caudais, pelo bico } \\
\text { reto e comprido e por nadar } \\
\text { com o pescoço ereto e } \\
\text { perpendicular à superfície da } \\
\text { água. } \\
\text { Movimentação abaixo d'água } \\
\text { Bico } \\
\text { Espesso, grosso } \\
\end{array}$ & $\begin{array}{l}\text { DRAE } \\
\text { Dicionário de } \\
\text { Tupi moderno } \\
\text { (BOUDIN, } \\
\text { 2005) }\end{array}$ \\
\hline Chile & Picurio & $\begin{array}{r}\text { Picu }=\text { Pico }= \\
\text { rio }=\end{array}$ & $\begin{array}{l}\text { Bico } \\
\text { Rio }\end{array}$ & $\begin{array}{l}\text { DRAE } \\
\text { Linguee }\end{array}$ \\
\hline Colômbia & $\begin{array}{l}\text { Zambullidor } \\
\text { piquigrueso } \\
\text { Zambullidor } \\
\text { piquipinto }\end{array}$ & $\begin{array}{r}\text { Zambullidor }= \\
\text { piqui }=\text { pico }= \\
\text { grueso }= \\
\text { pinto }=\end{array}$ & $\begin{array}{l}\text { Mergulhador } \\
\text { Bico } \\
\text { Espesso, grosso } \\
\text { De diversas cores } \\
\end{array}$ & \begin{tabular}{|l} 
DRAE \\
Linguee
\end{tabular} \\
\hline Costa Rica & $\begin{array}{l}\text { Zambullidor } \\
\text { piquipinto }\end{array}$ & $\begin{array}{r}\text { Zambullidor }= \\
\text { piqui }=\text { pico }= \\
\text { pinto }=\end{array}$ & $\begin{array}{l}\text { Mergulhador } \\
\text { Bico } \\
\text { De diversas cores }\end{array}$ & Linguee \\
\hline Cuba & $\begin{array}{l}\text { Zaramagullón } \\
\text { grande }\end{array}$ & $\begin{array}{r}\text { Somormujo }= \\
\text { grande }= \\
\end{array}$ & $\begin{array}{l}\text { Abaixo da água } \\
\text { Grande }\end{array}$ & DRAE \\
\hline Espanha & $\begin{array}{l}\text { Zaramagullón } \\
\text { grande }\end{array}$ & $\begin{array}{r}\text { Somormujo }= \\
\text { grande }=\end{array}$ & $\begin{array}{l}\text { Abaixo da água } \\
\text { Grande }\end{array}$ & DRAE \\
\hline Equador & $\begin{array}{l}\text { Zambullidor } \\
\text { piquipinto }\end{array}$ & $\begin{array}{r}\text { Zambullidor }= \\
\text { Piqui }=\text { pico }= \\
\text { pinto }=\end{array}$ & $\begin{array}{l}\text { Mergulhador } \\
\text { Bico } \\
\text { De diversas cores }\end{array}$ & Linguee \\
\hline Honduras & $\begin{array}{l}\text { Zambullidor } \\
\text { pico rayado }\end{array}$ & $\begin{array}{r}\text { Zambullidor }= \\
\text { pico }= \\
\text { rayado }=\end{array}$ & $\begin{array}{l}\text { Mergulhador } \\
\text { Bico } \\
\text { Listrado } \\
\end{array}$ & Linguee \\
\hline México & $\begin{array}{l}\text { Zambullidor } \\
\text { pico grueso } \\
\text { Zambullidor } \\
\text { picogrueso } \\
\text { Zambullidor } \\
\text { piquipinto } \\
\end{array}$ & $\begin{array}{r}\text { Zambullidor }= \\
\text { Piqui }=\text { pico }= \\
\text { grueso }= \\
\text { pinto }=\end{array}$ & $\begin{array}{l}\text { Mergulhador } \\
\text { Bico } \\
\text { Espesso, grosso } \\
\text { De diversas cores }\end{array}$ & \begin{tabular}{|l} 
DRAE \\
Linguee
\end{tabular} \\
\hline Nicarágua & $\begin{array}{l}\text { Zampullín } \\
\text { Piquipinto }\end{array}$ & $\begin{array}{r}\text { Zampullín }= \\
\text { Piqui }=\text { pico }= \\
\text { pinto }=\end{array}$ & $\begin{array}{l}\text { Mergulhão, ave ribeirinha } \\
\text { Bico } \\
\text { De diversas cores } \\
\end{array}$ & \begin{tabular}{|l} 
DRAE \\
Linguee
\end{tabular} \\
\hline Panamá & $\begin{array}{l}\text { Zambullidor } \\
\text { Piquipinto }\end{array}$ & $\begin{array}{r}\text { Zambullidor }= \\
\text { Piqui }=\text { pico }= \\
\text { pinto }=\end{array}$ & $\begin{array}{l}\text { Mergulhador } \\
\text { Bico } \\
\text { De diversas cores } \\
\end{array}$ & $\begin{array}{l}\text { DRAE } \\
\text { Linguee }\end{array}$ \\
\hline
\end{tabular}




\begin{tabular}{|c|c|c|c|c|}
\hline Paraguai & $\begin{array}{l}\text { Macá pico } \\
\text { grueso }\end{array}$ & $\begin{array}{r}\text { Macá = } \\
\text { do Tupi-Guarani } \\
\text { Macang ou } \\
\text { Muaka'í = } \\
\text { pico = } \\
\text { grueso = }\end{array}$ & $\begin{array}{l}\text { Palmípedes das áreas } \\
\text { lacustres, que se } \\
\text { caracterizam pela ausência } \\
\text { de penas caudais, pelo bico } \\
\text { reto e comprido e por nadar } \\
\text { com o pescoço ereto e } \\
\text { perpendicular à superfície da } \\
\text { água. } \\
\text { Movimentação abaixo d'água } \\
\text { Bico } \\
\text { Espesso, grosso }\end{array}$ & $\begin{array}{l}\text { DRAE } \\
\text { Linguee } \\
\text { Dicionário de } \\
\text { Tupi moderno }\end{array}$ \\
\hline Peru & $\begin{array}{l}\text { Zambullidor de } \\
\text { pico grueso }\end{array}$ & $\begin{array}{r}\text { Zambullidor }= \\
\text { pico }= \\
\text { grueso }=\end{array}$ & $\begin{array}{l}\text { Mergulhador } \\
\text { Bico } \\
\text { Espesso, grosso }\end{array}$ & Linguee \\
\hline Uruguai & $\begin{array}{l}\text { Zambullidor de } \\
\text { pico grueso }\end{array}$ & $\begin{array}{r}\text { Zambullidor }= \\
\text { pico }= \\
\text { grueso }=\end{array}$ & $\begin{array}{l}\text { Mergulhador } \\
\text { Bico } \\
\text { Espesso, grosso }\end{array}$ & Linguee \\
\hline Venezuela & Buzo & Buzo = & $\begin{array}{l}\text { Mergulhador, quem mergulha } \\
\text { debaixo d'água }\end{array}$ & DRAE \\
\hline
\end{tabular}

Fonte: Elaboração própria

\section{Considerações finais}

Diante da profusão de informações semânticas observadas nas descrições dos fraseotermos que denominam as aves estudadas nesta pesquisa, procedentes de 18 países hispanófonos dos 21 que têm o espanhol como língua oficial, pode-se afirmar que certas questões preliminares encontram resposta. Com efeito, o reflexo da cultura e da história desses países deixa vestígios linguísticos nas denominações das aves em língua espanhola. Uma delas é a influência das línguas indígenas, como o Mapuche no Chile, o Uto-asteca no México, o Tupi-Guarani no Paraguai, Venezuela e Argentina, o Caribe em Cuba, além de marcas etimológicas incertas em denominações registradas na Colômbia e na Espanha, mostrando uma resistência das línguas nativas ao processo de colonização pela imposição da língua dos colonizadores.

A análise léxico-semântica das denominações ainda revela a influência sociocultural sobre os fraseotermos investigados, uma vez que a visão que os habitantes de cada país têm sobre as aves, por exemplo, a percepção das cores, das formas, dos sons e compreensão dos lugares e dos hábitos de vida da avifauna refletem nas formas de denominação. Assim, as denominações podem encontrar suas origens nas crenças e lendas dos povos da comunidade de língua estudada. Cada povo nomeia os objetos de acordo com sua cultura e, cada objeto, pode ter vários nomes diferentes dependendo dela. 


\section{REFERÊNCIAS}

AULETE. dicionário online. Disponível em: http://www.aulete.com.br. Acesso em: 10 set. 2020.

AVIBASE. The World Bird Database. Disponível em: https://avibase.bsc-eoc.org/avibase. jsp. Acesso em: 20 jul. 2020.

BARROS, L. A. Conhecimentos de terminologia geral para a prática tradutória. São José do Rio Preto: NovaGraf, 2007.

BIDERMAN, M. T. C. Os dicionários na contemporaneidade: arquitetura, métodos e técnicas. In: OLIVEIRA, A. M. P. P.; ISQUERDO, A. As ciências do léxico: lexicologia, lexicografia, terminologia, v. 2, 2001.

BOUDIN, M. H. Dicionário de tupi moderno: Dialeto tembé-ténetéhar do alto do rio Gurupi. São Paulo: Conselho Estadual de Artes e Ciências Humanas, 1978.

BOULANGER, J.-C. Une lecture socioculturelle de la terminologie. Cahiers de linguistique sociale, n. 18, p. 13-30, 1991.

BOURIGAULT, D.; SLODZIAN, M. Pour une terminologie textuelle. Terminologies nouvelles, V. 19, p. 29-32, 1999.

CABRÉ, M. T. Terminologie: théorie, méthode et applications. Ottawa: Les presses de I'Université d'Ottawa, Armand Colin, 1998.

FAULTSTICH, E. A Socioterminologia na comunicação científica e técnica. Ciência e Cultura, São Paulo, v. 58, n. 2, p. 27-31, jun. 2006.

FERNANDES, I. M.; SIGNOR, C. A.; PENHA, J. Biodiversidade no Pantanal de Poconé. Cuiabá: Centro de Pesquisa do Pantanal, p. 36-38, 2010.

FRISCH, J. D.; FRISCH, C. D. Aves brasileiras e plantas que as atraem. Dalgas Ecoltec, 2005.

GAUDIN, F. Socioterminologie. Une approche sociolinguistique de la terminologie. Bruxelles: Éditions Duculot, 2003.

GAUDIN, F. Pour une Socioterminologie. Rouen: Publication de l'université de Rouen, 1993. 
GONZÁLEZ-REY, M. I. La phraséologie du français. Toulouse: Presses universitaires du Mirail, 2015.

GOUADEC, D. Extraction, description, gestion e explication de entités phraséologiques. Terminologies Nouvelles, v. 10, Bélgica, RINT, p. 83-91, 1993.

LERAT, P. Les langues spécialisées. Paris: Presse Universitaire de France, 1995.

L'HOMME, M-C. Sur la notion de terme. Meta: journal des traducteurs, v. 50, n. 4, p. 1112-1132, 2005.

L'HOMME, M-C. La terminologie: principes et techniques. Montréal: Les presses de l'université de Montréal, 2004.

LINGUEE. Dicionário Online. Disponível em: https://www.linguee.es. Acesso em: 10 fev. 2020.

MARTINET, A. Le synthème. In: La Linguistique, n. 35, v. 2, 1999.

MORTUREUX, M.-F. La dénomination, approche socio-linguistique. Langages, 19e année, n76, La dénomination, p. 95-112, 1984.

PAMIES BERTRÁN, A. Aux limites du limitrophes: à propos des catégories phraséologiques. In: SFAR, I., BUVET, P.-A. (coord.). La phraséologie entre fixité et congruence. Louvain-laNeuve: Academia l'Harmattan, 2018.

PETIT, G. La dénomination: approches lexicologique et terminologique. Louvain: Éditions Peeters, 2009.

PIACENTINI, V. Q.; ALEIXO, A.; AGNE, C. E.; MAURICIO, G. N. Lista comentada das aves do Brasil pelo Comitê Brasileiro de Registros Ornitológicos. Revista Brasileira de Ornitologia, v. 23, n. 2, p. 91-298, 2015.

REAL ACADEMIA ESPAÑOLA. Diccionario de la Lengua Española. Disponível em: https://dle. rae.es. Acesso em: 20 set. 2020.

REY, A. La terminologie: noms et notions. Paris: PUF, 1979. 
SALVATI, S. S.; MILONE, P. C. Ecoturismo no pantanal brasileiro e boliviano: estudo de políticas e alternativas sustentáveis. São Paulo: Universidade de São Paulo, 2002.

SAPIR, E. Linguística como ciência. Rio de Janeiro: Acadêmica, 1969.

THOIRON, P. La terminologie multilingue: une aide à la maîtrise des concepts. Meta, v. 39, n. 4, p. 765-773, 1994. Disponível em: https://id.erudit.org/iderudit/004482ar. Acesso em 10 fev. 20.

UNESCO. Aire de conservation du Pantanal, 2000. Disponível em: http://whc.unesco.org/fr/ list/999. Acesso em: 04 set. 2020.

WÜSTER, E. Introducción a la teoría general de la terminología y a la lexicografía terminológica. Barcelona: Universitat Pompeu Fabra, Documenta Universitaria, 1998. 